\title{
Effects of Rotor Speed on Peroxide/Bismaleimide Cured Polypropylene/Nitrile Rubber Thermoplastic Vulcanizates (TPVs)
}

\author{
Anna Paula Azevedo de Carvalho ${ }^{a}$, Ketly Pontes Soares ${ }^{b}$, Danielle Ferreira dos Santos ${ }^{a}{ }^{\circledR}$, \\ Bluma Guenther Soares ${ }^{a, b}$, Alex da Silva Sirqueira $^{c, d} * \mathbb{0}$ \\ anstituto de Macromoléculas, Universidade Federal do Rio de Janeiro, 21941-598, Rio de Janeiro, RJ, \\ Brasil \\ ${ }^{b}$ Instituto Alberto Luiz Coimbra de Pós-Graduação e Pesquisa de Engenharia-COPPE, Universidade \\ Federal do Rio de Janeiro, 21941-972, Rio de Janeiro, RJ, Brasil \\ 'Laboratório de Engenharia de polímeros, Fundação Centro Universitário Estadual da Zona Oeste, \\ 23070-200, Rio de Janeiro, RJ, Brasil \\ dPrograma de Pós-Graduação em Engenharia Química, Universidade Federal Rural do Rio de Janeiro, \\ Rio de Janeiro, RJ, Brasil
}

Received: March 16, 2018; Revised: June 07, 2018; Accepted: July 09, 2018

\begin{abstract}
Elastomer thermoplastics are a class of polymeric materials that received industry attention due to the possibility of joining the elastic of elastomers with the thermoplastics processability. The synergistic properties are linked to the appropriate processing. This study evaluated the effect of rotor speed during polymer mixing and the dynamic vulcanization process of polypropylene and nitrile rubber blends. Bismaleimide was employed as multipurpose agent (crosslinking coagent for peroxide and compatibilizer). Morphology, mechanical properties, compression set and oil resistance tests were evaluated for compositions containing 50 and 70 PHR of elastomer. The compatibilization of TPV was realized by infrared spectroscopy. It was shown a compatibilizer effect and better dispersion, achieving the inversion phase, only studying the effect of processing conditions (rotor speed, addition sequence, additives), without any extra interfacial agent. There is a tendency to obtain better performance with decrease speed at dynamic vulcanization or/and at torque stabilization, mainly for blends with 50 PHR of rubber.
\end{abstract}

Keywords: Processing, TPV, PP, NBR, vulcanization.

\section{Introduction}

Thermoplastic vulcanizates (TPV) are compounds formed by thermoplastics such as Polypropylene (PP), Polyamide (PA), Polyethylene (PE) with elastomers such as Natural Rubber (NR), Ethylene Propylene Diene Rubber (EPDM) and Nitrile Rubber (NBR) ${ }^{1-4}$. NBR can afford the combination of good mechanical properties and oil resistance, which make it very desirable for the automotive industry. The elastomeric phase is dispersed in the thermoplastic matrix and the vulcanization occurs during the melt processing (dynamic vulcanization techniques), obtained by extrusion or internal mixer.

The good rubber dispersion into plastic matrix favors the interaction between the pairs, resulting in a material that can join the elastic properties of elastomers with the processing ease and recyclability of thermoplastics ${ }^{5}$. However, the synergistic properties - not only by the interaction between the pairs (similar blends) - are mainly defined through the adequate processing ${ }^{6}$. The processing variables such as thread profile, temperature, residence time, speed, rotor type, and processing additives have an influence on the

*e-mail: assirqueira@gmail.com
TPV performance. The rotor speed is an important factor for internal mixers because, generally, when the rotor speed has increased an economy, it occurs in the mixing time. But, high speed generates a rise in the power consumed by increasing the energy of rotational torque ${ }^{7,8}$.

It is important to highlight the role of crosslinking agents and processing enhance. In the case of TPV, crosslinking agents can be by sulfur, phenolic or peroxide systems. The peroxide cure system is usually made by a pair of coagent/ peroxide and is usually used bismaleimide (BMI) and dicumyl peroxide (DCP) for TPV with high performance. BMI is a polar coagent with good miscibility and compatibility with polar rubbers, such as NBR, that can form coagent bridges between rubber chains improving the crosslinking density, besides the cure $^{9}$. Furthermore, this coagent can act as a multifunctional radical acceptor to allow the combination of dissimilar polymer radicals to give a copolymer by the formation of coagent bridges between rubber and PP chains as extra crosslinking. The compatibilizer effect of BMI was also suggested for PP/NBR blends by Soares group ${ }^{10}$, BMI can do crosslinking coagent and compatibilizer. In previous studies, it was reported the use of plasticizers to facilitate the processing of the rubber even in this TPV composition ${ }^{10-12}$. 
Plasticizers can be a processing aid at melt temperature, but a softener in the finished part, compromising the modulus. When a crosslinking system based on peroxide is used, the plasticizers (e.g. dioctyl phthalate) can promote side reactions by transfer radical mechanism, which competes with the main crosslinking process and, very often, compromises vulcanization efficiency ${ }^{9}$. Then, the use of plasticizers should be avoided in rubber formulations crosslinked with peroxides. In view of this, the choice of mode and addition sequence of the processing components of this work offers the choice of not needing any plasticizer.

Crosslinked PP/NBR blends were reported by several authors to focus on interfacial interaction using different compatibilizer agents ${ }^{10,13-19}$, but no study involving TPV with focus on processing conditions was carried out previously. To the best of our knowledge, this work was the first to evaluate processing conditions of a TPV minimizing problems of incompatibility, nevertheless, focusing only in processing condition and parameters of dynamic vulcanization - without any other compatibilizing agents or plasticizers ${ }^{8}$. Also, it was shown by FTIR technique the interaction between PP and NBR provided by coagent. The torque rheometer curves supplied by internal mixers were used to determine the vulcanization and processing characteristics of elastomers compounds.

\section{Materials}

$\mathrm{PP}$ (melt flow index $=3.5 \mathrm{~g} / 10 \mathrm{~min}$ at $230^{\circ} \mathrm{C} / 2.16 \mathrm{Kg}$ ) was provided by Braskem S/A, RS, Brazil. NBR (NBR-608) $33 \mathrm{wt} \%$ acrylonitrile; Money viscosity (ML $1+4$ at $\left.100^{\circ} \mathrm{C}\right)$ was supplied by Nitriflex Ind. Com. S/A, RJ, Brazil. BMI (HVA-2) was purchased from Dupont Dow Elastomers (SP, Brazil). Dicumyl peroxide (DCP) (99\%) was supplied by Retilox, SP, Brazil. Naugard 445 (antioxidant) purchased from Crompton.

\section{Experimental}

\subsection{Preparation of TPV}

The preparation of PP/NBR TPV was performed by melt mixing using a Brabender Plastograph $®$ computerized Torque Rheometer (Duisburg, German), equipped with Banbury rotors, at $185^{\circ} \mathrm{C}$, total mixing time of 9 minutes with different rotation speed profiles. The materials were added into the mixer in the following sequence: 1) PP (30 PHR), NBR (70 PHR), 2) crosslinking system BMI (1.4 PHR) + DCP (0.7 PHR) and 3) antioxidant (0.7 PHR). All the components were added with 2 minutes to process each one and 1 minute more, in the end, for better homogenization of all components. It was also evaluated the effect of the composition (mixing $\mathrm{PP} / \mathrm{NBR}$ in a proportion of $50 / 50$ PHR), the amount of crosslinking agents was corrected for this NBR content, preserving the ratio 1.4/0.7 (BMI/DCP).
The TPV's were mixed with different rotation speed profiles, varying the rotor speed in the vulcanization, antioxidant and stabilization step times. These propositions were performed to achieve the better dispersion of crosslinked rubber in the thermoplastic phase after dynamic vulcanization. The torque curve can be divided into three stages: mixing, vulcanization and torque stabilization. The rotation speed profiles used are described below (Table 1, shows the variation):

- V1: Rotation speed of $60 \mathrm{rpm}$ during the entire mixing process.

- V2: Decrease initial rotation speed from $60 \mathrm{rpm}$ to $40 \mathrm{rpm}$ at vulcanization.

- V3: Reduce initial rotation speed from $60 \mathrm{rpm}$ to $40 \mathrm{rpm}$ at vulcanization moment with a return to initial rotor speed at torque stabilization stage.

- V4: Increase initial rotation speed from $60 \mathrm{rpm}$ to 80 rpm at vulcanization moment with a return to initial rotor speed at the moment of torque stabilization.

The TPV produced was injection-molded at $240^{\circ} \mathrm{C}$, under pressure of 350 bar and back-pressure of 250 bar during 5 seconds, in a Haake mini-injector (model miniJet). Cylindrical test specimens $(12.5 \mathrm{~mm}$ diameter and $6.0 \mathrm{~mm}$ thickness) and dog-bone shaped specimen (ASTM D638 IV type) were injected to perform the oil swelling and tensile tests, respectively.

\subsection{Fourier transform infrared spectroscopy (FTIR)}

FTIR transmittance spectra was recorded on a Thermo Scientific Nicolet iS50 FT-IR spectrometer using the $\mathrm{KBr}$ pastille method to BMI and Attenuated Total Reflection (ATR) technique to PP, NBR, and blends. All spectra data were obtained in the range from 4000 to $500 \mathrm{~cm}^{-1}$, the spectral resolution of $6 \mathrm{~cm}^{-1}$ and 32 scans.

\subsection{Differential scanning calorimetry (DSC)}

DSC measurements of the PP/NBR TPV's, neat PP and NBRs were carried out using a DSC 204 F1 Phoenix ${ }^{\circledR}$ from Netszch, operating in dynamic mode, at $20^{\circ} \mathrm{C} / \mathrm{min}$, from -50 to $300^{\circ} \mathrm{C}$, under nitrogen atmosphere $(50 \mathrm{~mL} / \mathrm{min})$ on samples of $\sim 10 \mathrm{mg}$. The first heating scan was employed to erase the thermal history. The melting temperature $\left(\mathrm{T}_{\mathrm{m}}\right)$ and heat of fusion $\left(\Delta \mathrm{H}_{\mathrm{f}}\right)$ of each sample were determined from the maximum and the area of melting endothermic peaks, respectively, in the second heating scan. The crystallization

Table 1. Rotor speed profiles.

\begin{tabular}{cccc}
\hline \multirow{2}{*}{ Code } & Mixing & Vulcanization & Stabilization \\
\cline { 2 - 4 } & 2 minutes & 2 minutes & 3 minutes \\
\hline V1 & 60 & 60 & 60 \\
V2 & 60 & 40 & 40 \\
V3 & 60 & 40 & 60 \\
V4 & 60 & 80 & 60 \\
\hline
\end{tabular}


temperature $\left(T_{c}\right)$ was directly determined from the maximum of an exothermic peak in the first cooling scan. The degree of crystallinity $\left(\mathrm{X}_{\mathrm{c}}\right)$ of PP phase was obtained from the ratio of normalized $\Delta \mathrm{H}$ of the PP on TPVs to $\Delta \mathrm{H}$ of $100 \%$ crystalline $\operatorname{PP}\left(X_{c}=\Delta H_{f} / \Delta H_{o}\right)$, were $\Delta \mathrm{H}^{\circ}=207 \mathrm{~J}^{-\mathrm{g}^{-120}}$.

\subsection{Physical properties}

Tensile tests were realized using a Universal Machine Test (EMIC model 422 - Brazil) at room temperature according to ASTM D638 at a cross-head speed of $100 \mathrm{~mm} / \mathrm{min}$. The Shore D hardness was performed according to ASTM D2240 (Bareiss Hardness - Germany). The Compression set tests were performed according to the ASTM D2395-85 by B method ${ }^{21}$. After recording the initial dimensions of the specimens, the tests were realized by pressing specimens to $25 \%$ of its original thickness, and aged in an air oven controlled ventilation at $100^{\circ} \mathrm{C}$ for a period of 22 hours. Then, dimensions recovered upon release of the compressive force were measured and the percentage of residual deformation was determined.

\subsection{Oil swelling test}

The swelling percentage in motor oil (IRM903) was determined according to ASTM D471-10 - using the procedure for mass changes with test results calculated from the average of three specimens. The samples were immersed in IRM903 oil at $80^{\circ} \mathrm{C}$ for 72 hours of aging. Then, the materials was removed from the oil and dried with a tissue paper. The sample mass, after aging, was determined to assess the swelling degree.

\subsection{Scanning electron microscopy}

The morphology of PP/NBR TPVs was evaluated by scanning electron microscopy (SEM) using a JEOL 2000FX equipment, with backscattering electron detector and voltage of $20 \mathrm{kV}$. The samples were cryogenically fractured and surfaces were treated with osmium tetroxide $\left(\mathrm{OsO}_{4}\right)$ solution for 12 hours to mark selectively the NBR phase. After that, the samples were coated with a thin layer of carbon to avoid electrostatic charging during observation by SEM.

\section{Results and Discussion}

\subsection{Torque rheometer}

The Brabender Plastograph ${ }^{\circledR}$ data obtained from PP/NBR (30/70 PHR) are shown in Figure 1. The low torque values in the initial stages are due to the easy processing typical by thermoplastic material. The NBR addition into melting PP is observed a sudden increase in torque values because the higher shear strength offered by rubbers (infusible, high molecular weight, etc.) makes the process more difficult, demanding more energy to process. At the same time, after 2 minutes of the mixer the torque values drop to approximately

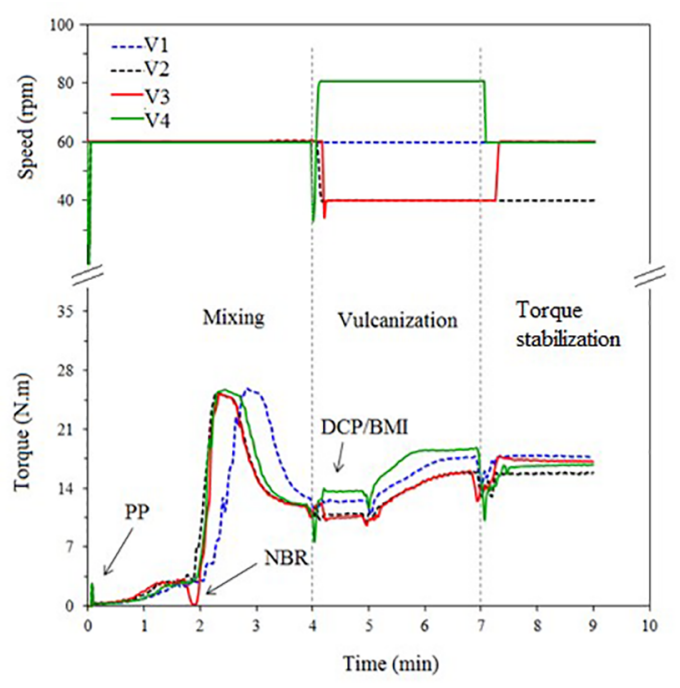

Figure 1. Evolution of actual rotor speed and torque with mixing time as a function of rotor speed profile at dynamic vulcanization of PP/NBR (30/70 phr): V1 (blue dashed line), V2 (black dashed line), V3 (red line) and V4 (green line).

10 N.m. It is an indicative that the addition of PP as the first component in a TPV processing is good, because enhance the polymer blend.

The decrease (V3) or increase (V4) in speed during dynamic vulcanization shows final torque lowers than torque maintenance at the same speed (V1). It can be observed that these processing conditions caused inversion in the torque value after vulcanization (V3 $>$ V4). In the literature, it is reported that higher mixer speeds are necessary for good processing properties ${ }^{7}$, in our studies, the higher shear rate may have been too high that can kindle some level of polymer degradation. The final torque of reducing speed for $40 \mathrm{rpm}$ and return to $60 \mathrm{rpm}$ (V3) was similar to a constant speed (V1). This behavior suggests that the vulcanization process requires low mixing energy to be effective. However, after the networking formation, it has to be dispersed into thermoplastic matrix which may be favored by the increase in rotor speed.

The profiles V1 and V3 give better behavior (high final torque). The profiles were used in a mixer with 50 PHR of elastomeric, to compare the influence of processing speed, Figure 2. The final torque was high when decreased the speed at the vulcanization moment (V3) than keeping it constant (V1). This action appears to be less aggressive to TPVs and stop the possible premature materials degradation.

Table 2 shows the processing conditions employed in TPVs processing. The polymers rheological properties are the most important to the mixer production because it affects all process involved. The torque rheometer reproduces the geometries of industrial equipment and approaches to the real processing situations. Although it is not possible to transform directly the measured torque into apparent viscosity, it is possible to have an understanding of the melting viscosity 


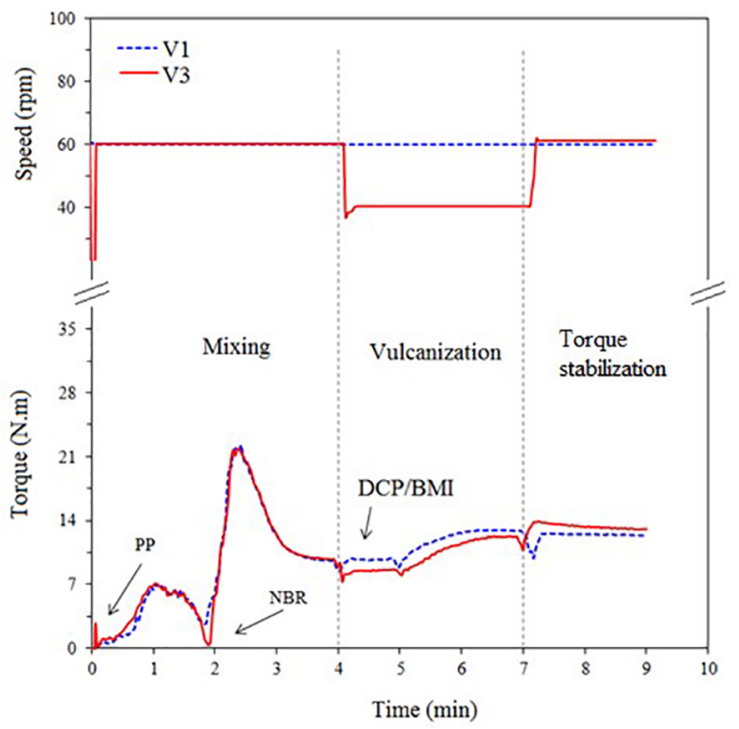

Figure 2. Evolution of actual rotor speed and torque with mixing time as a function of rotor speed profile at dynamic vulcanization of PP/NBR (50/50 phr) TPVs: V1 (blue dashed line) and V3 (red line).

mixture behavior. By Table 2, it can be seen the values of initial and maximum torques at vulcanization step (4 to 7 minutes), and the final torque.

Processing TPV in the condition V1 $(60 / 60 / 60 \mathrm{rpm})$ and V3 (60/40/60 rpm) provides a higher final torque for all concentration of NBR (50 and 70 PHR). It suggests better dispersion of vulcanized domains in thermoplastic phase. The energy consumptions are due to rubber amount in the mixtures, which in smaller quantities facilitates the processing because there is no greater shear resistance. The entire mixer presents the same temperature profile.

\subsection{FTIR analysis}

The FTIR spectra of neat NBR, neat PP, TPVs with 70 and 50 PHR of NBR are shown in Figure 3 Figure 4. In neat
PP spectra the peaks at 2837, 2868, 2916, 2949 and 1456, $1376 \mathrm{~cm}^{-1}$ are assigned to the $\mathrm{C}-\mathrm{H}$ stretching vibrations and $-\mathrm{CH}_{2},-\mathrm{CH}_{3}$ bending vibrations, respectively, in PP chains $^{22}$. Furthermore, three bands appear at 1166, 997 and $973 \mathrm{~cm}^{-1}$ corresponds to $-\mathrm{CH}_{3}$ symmetric deformation and $-\mathrm{CH}_{3}$ rocking vibrations of $\mathrm{PP}{ }^{22}$. It is noted by the NBR spectra the peak at $2236 \mathrm{~cm}^{-1}$ relative to the characteristic alkyl $\mathrm{C} \equiv \mathrm{N}$ stretching vibration of acrylonitrile; the absorption bands at around 1586, 1440 and $968 \mathrm{~cm}^{-1}$ are assigned to $-\mathrm{CH}_{2},-\mathrm{CH}_{3}$ stretching vibration and to the $\mathrm{C}-\mathrm{H}$ wagging motions of butadiene stretching vibration, respectively ${ }^{3}$.

Comparing PP and NBR spectrum, it can be observed changes in some absorption bands to all TPVs. It may be indicative of the crosslinking process promoted by the curing system using DCP and BMI. That can reduce the interfacial tension resulted in compatibilizer effect. These absorptions can be seen by three enlargements of the spectra.

At the first level of observation, Figure 3.I (C-H stretching region) shows to all TPVs a tendency to the disappearance of the peak at $2868 \mathrm{~cm}^{-1}$ of PP. The shift of the C-H stretching vibrations from ca. 2837 and ca. $2851 \mathrm{~cm}^{-1}$ in PP and NBR chains, respectively, to approximately ca. $2840 \mathrm{~cm}^{-1}$ were noticed. The appearance of weak bands absorptions at 915 $\mathrm{cm}^{-1}$ (C-H bending for mono-substituted alkenes) ${ }^{23}$ and 1636 $\mathrm{cm}^{-1}$ (allyl C=C) ${ }^{23}$ are present. The shift of the $\mathrm{C}-\mathrm{H}$ stretching vibrations from ca. 973 and ca. $968 \mathrm{~cm}^{-1}$ in PP and NBR chains, respectively, to approximately ca. $965 \mathrm{~cm}^{-1}$ (showed by Figure 3.III) and the disappearance of the NBR band at $1586 \mathrm{~cm}^{-1}$ assigned to $-\mathrm{CH}_{2}$ stretching vibration (Figure 3.II). All these observations suggest a structural change at the hydrocarbons sites $\left(-\mathrm{CH}_{2}\right)$ promoted by hydrogen abstraction mechanism on PP and NBR using BMI as coagent for the crosslinking system (Figure 5). It is noticed (Figure 3.II) the appearance of the band at around $1715 \mathrm{~cm}^{-1}$ corresponding to the carbonyl stretching vibration of the imide $\mathrm{I}(-\mathrm{C}=\mathrm{O})$. On the other hand, assuming that besides reaction occurred, maleimide group can be transformed to saturated analog

Table 2. Processing parameters supplied by torque rheometer as a function of the rotor speed.

\begin{tabular}{|c|c|c|c|c|c|}
\hline \multirow{2}{*}{$\begin{array}{l}\text { Rotor speed } \\
\text { profile }\end{array}$} & \multicolumn{2}{|c|}{ Torque during vulcanization (N.m) } & \multirow{2}{*}{ Final torque (N.m) } & \multirow{2}{*}{ Final temperature $\left({ }^{\circ} \mathrm{C}\right)$} & \multirow{2}{*}{ Energy $(\mathbf{k J})$} \\
\hline & Initial & Maximum & & & \\
\hline \multicolumn{6}{|c|}{ PP/NBR 30/70 } \\
\hline V1 & 12.6 & 17.7 & 17.8 & 200 & 42.98 \\
\hline $\mathrm{V} 2$ & 10.3 & 15.8 & 15.6 & 193 & 32.00 \\
\hline V3 & 10.5 & 17.1 & 17.3 & 198 & 35.00 \\
\hline V4 & 13.6 & 17.7 & 16.0 & 200 & 50.07 \\
\hline \multicolumn{6}{|c|}{ PP/NBR 50/50 } \\
\hline V1 & 9.8 & 12.4 & 12.0 & 194 & 34.97 \\
\hline V3 & 8.5 & 13.0 & 13.2 & 194 & 30.69 \\
\hline
\end{tabular}

$\mathrm{V} 1=60 / 60 / 60 \mathrm{rpm}$;

$\mathrm{V} 2=60 / 40 / 40 \mathrm{rpm}$;

$\mathrm{V} 3=60 / 40 / 60 \mathrm{rpm}$;

$\mathrm{V} 4=60 / 80 / 60 \mathrm{rpm}$. 


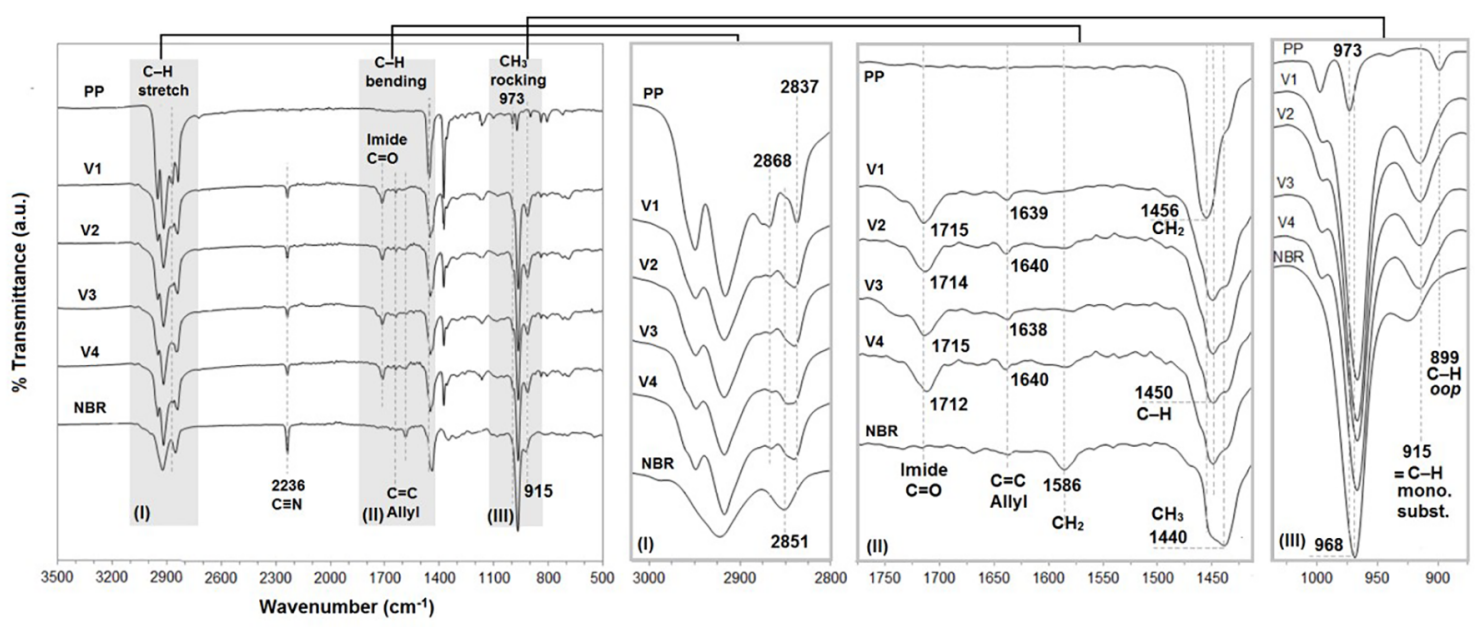

Figure 3. Typical ATR-FTIR spectra of neat PP, neat NBR and PP/NBR (30/70) TPV mixers by different rotor speed profile: C-H stretch regions (I and III) and Carbonyl region (II). V1=60/60/60 rpm; V2=60/40/40 rpm; V3=60/40/60 rpm; V4=60/80/60 rpm.
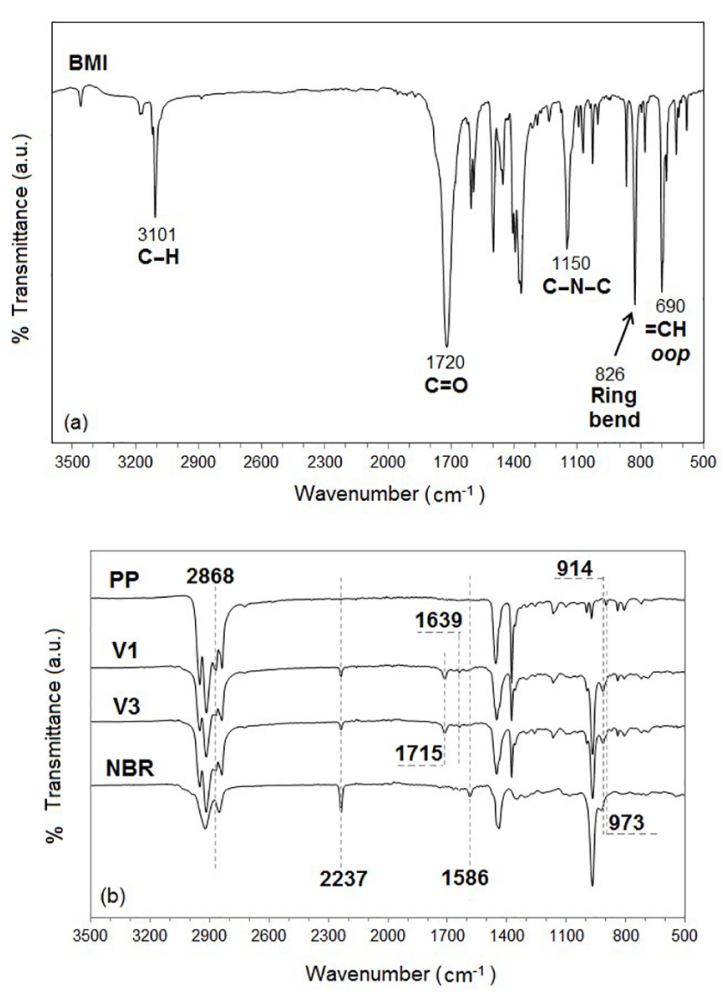

Figure 4. FTIR spectra of neat BMI by $\mathrm{KBr}$ method (a) and Typical ATR-FTIR spectra of neat PP, neat NBR and PP/NBR (50/50) TPV mixers by different rotor speed profile (b). $\mathrm{V} 1=60 / 60 / 60 \mathrm{rpm}$ and $\mathrm{V} 3=60 / 40 / 60 \mathrm{rpm}$.

succinimide ${ }^{25}$. This suggestion is based on the loss of the bending modes characteristic of maleimide at $690 \mathrm{~cm}^{-1}$ (ringbending) and $826 \mathrm{~cm}^{-1}(=\mathrm{CH} \text { out of plane })^{24,25}$ (see Figure 4-a). Comparing Figure 3 to Figure 4-b, no significant changes were observed between the variation in speed profiles and NBR content in the blends.

\subsection{Mechanical properties}

The mechanical properties of tensile test and shore D hardness are shown in Table 3. It can be noticed a tendency to gain in elongation at break for the blends with a minor fraction of NBR. It can be explained by the compatibilizer effect of BMI employed as the coagent of the crosslinking system - which can reduce the tension and improve the interaction between the immiscible phases, highlighting the contributions of booth PP and NBR phases, as mentioned previously in this work. The V1 speed profile promotes the better elongation at break. This result shows clearly the improvement at compatibilization caused by the choice of sequence addition of components into internal mixer used in this work (PP first, NBR later and vulcanization agent in sequence), and it was better than the one founded before by others groups ${ }^{10,11,15}$. The greater combination of mechanical properties was achieved to the mixture with $50 \mathrm{phr}$. The Shore D hardness values do not vary significantly. It is well known that the hardness is a property defined, above all, by the content of PP in reason of crystallinity.

The results of compression set (lower percentage indicate better TPV performance) of vulcanized compounds (Figure 6-a). When submitted to high temperatures, the TPV resistance is quite dependent on factors such as chemical nature of the polymer and vulcanization system. The use of NBR with lower contents of ACN is recommended to achieve better resistance to this type of deformation. The crosslinking system based on peroxide is more indicated, especially by the C-C bonds. The compression set gives the better results for the mixtures with the major content of NBR, expected a result as a function of the composition, and for the TPVs processed reducing the rotor speed during and after vulcanization (V1 and V2). This data is an agreement of torque rheometer values. It shows the better efficiency at dynamic vulcanization reducing the rotation speed since the higher crosslink density, the better the resistance permanent 


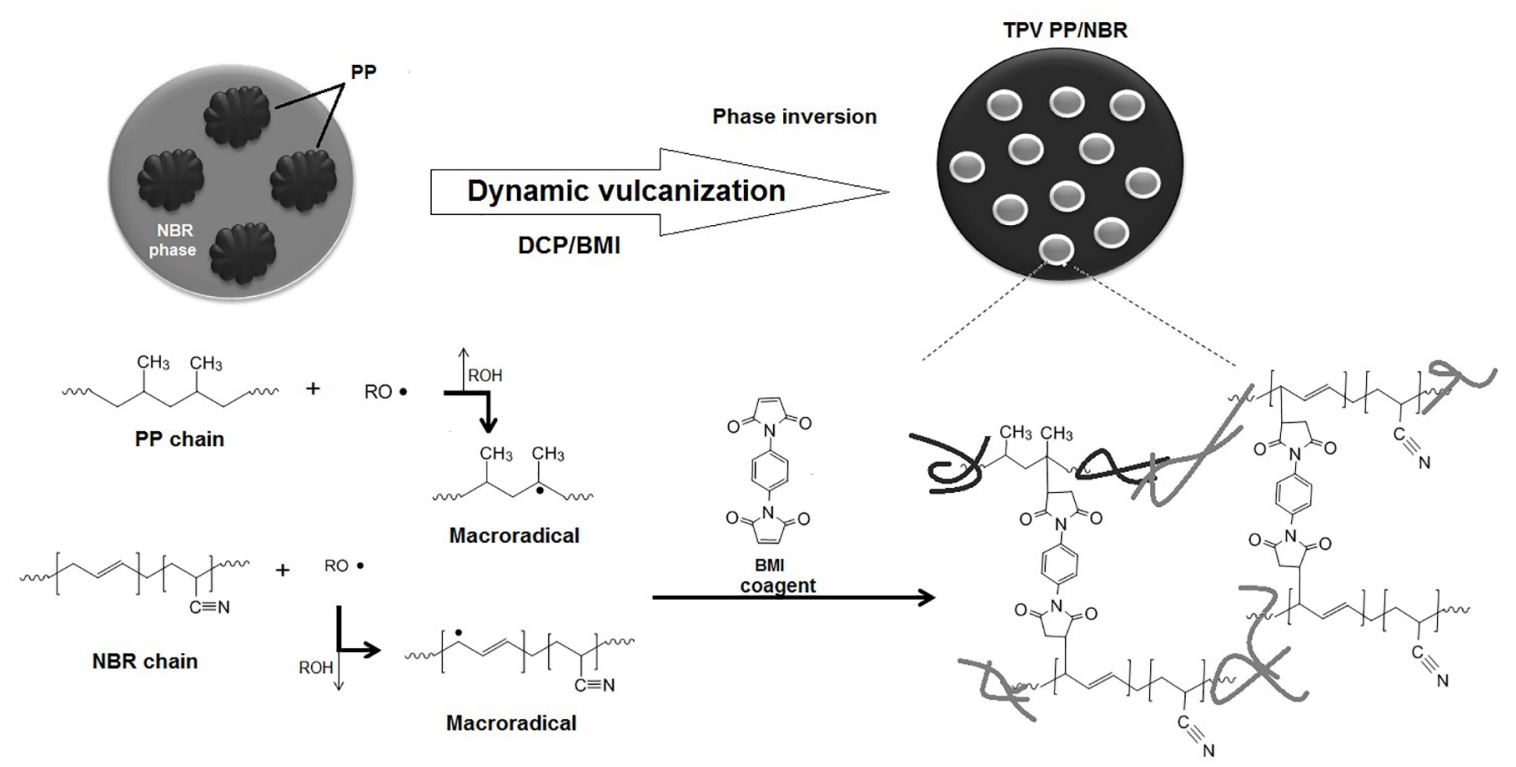

Figure 5. Schematic representation of the proposed mechanism of interaction between BMI and mixture components.

Table 3. Mechanical properties of TPVs as a function of rotor speed.

\begin{tabular}{ccccc}
\hline Rotor speed profile & Stress (MPa) & Elongation at break (\%) & Young's modulus (Mpa) & Shore D Hardness \\
\hline & & PP/NBR 30/70 & 33 \\
V1 & $10.89 \pm 0.5$ & $479 \pm 68$ & $23.71 \pm 1.62$ & 34 \\
V3 & $11.06 \pm 0.3$ & $463 \pm 33$ & $21.37 \pm 1.37$ & 33 \\
V4 & $11.27 \pm 0.7$ & $481 \pm 61$ & $22.24 \pm 1.35$ & 34 \\
\hline V1 & $11.25 \pm 0.7$ & $512 \pm 40$ & $47.50 \pm 0.77$ & 38 \\
V3 & $14.07 \pm 0.9$ & $596 \pm 78$ & $44.75 \pm 6.16$ & 41 \\
\hline
\end{tabular}

$\mathrm{V} 1=60 / 60 / 60 \mathrm{rpm} ;$

$\mathrm{V} 2=60 / 40 / 40 \mathrm{rpm} ;$

$\mathrm{V} 3=60 / 40 / 60 \mathrm{rpm}$

$\mathrm{V} 4=60 / 80 / 60 \mathrm{rpm}$.

deformation under a given deflection and temperature range presented by material ${ }^{26}$.

The oil swelling degree is a measurement of TPV oil resistance. It is a property highly desired in TPVs due to the wide application in the automotive industry, which will remain in contact with oils, greases, and solvents. The oil resistance using IRM903, represented by swelling in Figure 6-b, was low for booth compositions with 70 and 50 phr of rubber, when the dynamic vulcanization is performed at V3 speed profile. This result, using the conditions proposed, was better than in previous research ${ }^{10}$. The formation of the three-dimensional network in the elastomeric phase decreases the chain segment joining two successive crosslinking points preventing the penetration of the oil molecules, reducing the oil absorption capability. The oil swelling confirms the better effect of lower rotation speed at dynamic vulcanization, corroborates the compression set and can prove that rotation speed of the mixer influences into final material ${ }^{27}$ promoting the good elasticity to TPV. In addition, the properties presented here bring the expectative of better reprocessing conditions due to major quantities of PP. The tensile properties were most affected by compatibilization while the compression set and oil resistance are mainly affected by dynamic vulcanization and rubber concentration.

\subsection{Morphology}

Changes in morphology occurring during processing should be well understood in order to relate them to the final properties of the blend ${ }^{19}$. Figure 7 and 8 shows the micrographs of the cryogenically fractured surface of TPVs - to maintain the integrity of the morphology structure defined during the dynamic vulcanization process. The NBR phase appears like 

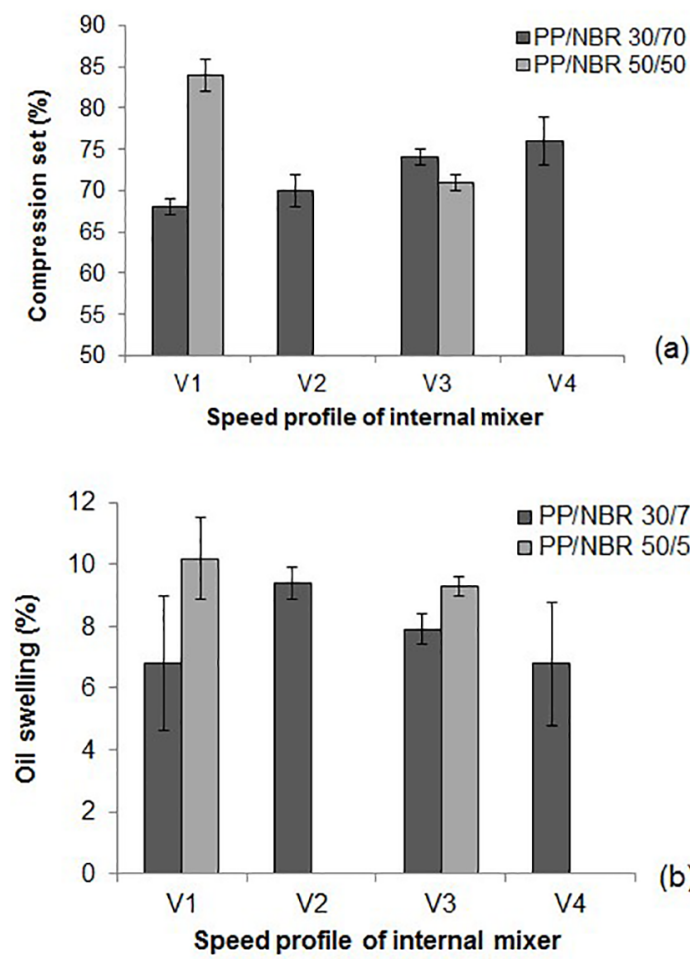

(b)

Figure 6. Compression set (a) and oil resistance (b) of the TPVs as a function of the rotor speed of internal mixer: PP/NBR 30/70 (grey) and PP/NBR 50/50 (light grey). V1 $=60 / 60 / 60 \mathrm{rpm} ; \mathrm{V} 2=60 / 40 / 40$ rpm; V3=60/40/60 rpm; V4=60/80/60 rpm. a white region due to the selective dyeing performed with osmium and the PP phase like a thinner and dark region for PP/NBR (30/70) attributed to the low PP content. The effect of rotor speed: the TPV processed with V1 $(60 / 60 / 60 \mathrm{rpm})$ and V2 (60/40/40 rpm) speed profile (Figure 7-a) has a slightly higher homogeneous morphology dispersed on PP matrix, with minor and more well-defined NBR domains, also with more tendency to spherical form. It also can be observed to PP/NBR (30/70) processed by V3. It is in accordance with the literature ${ }^{28,29}$, which accepts that even for compositions with higher rubber content, the thermoplastic becomes the matrix and the elastomer vulcanizes the dispersed phase. It can reflect a better interaction of PP and NBR, increasing the interfacial adhesion and interfacial area. It is well known that the size of vulcanized domains has an important effect on tensile properties such as strength and elongation at break: when the average domains diameter of elastomeric phases decrease, the TPV mechanical performance is improved ${ }^{(10,19)}$. The morphology may explain the tensile and physical properties previously discussed. The compatibility action derived from the copolymer formed between PP and NBR phases promoted by the use of BMI coagent, which has been further improved with the reduction of mixer speed at the curing and torque stabilization moments in the TPV fabrication. It has been observed that the composition has an influence on the phase inversion phenomena ${ }^{28-30}$ and,
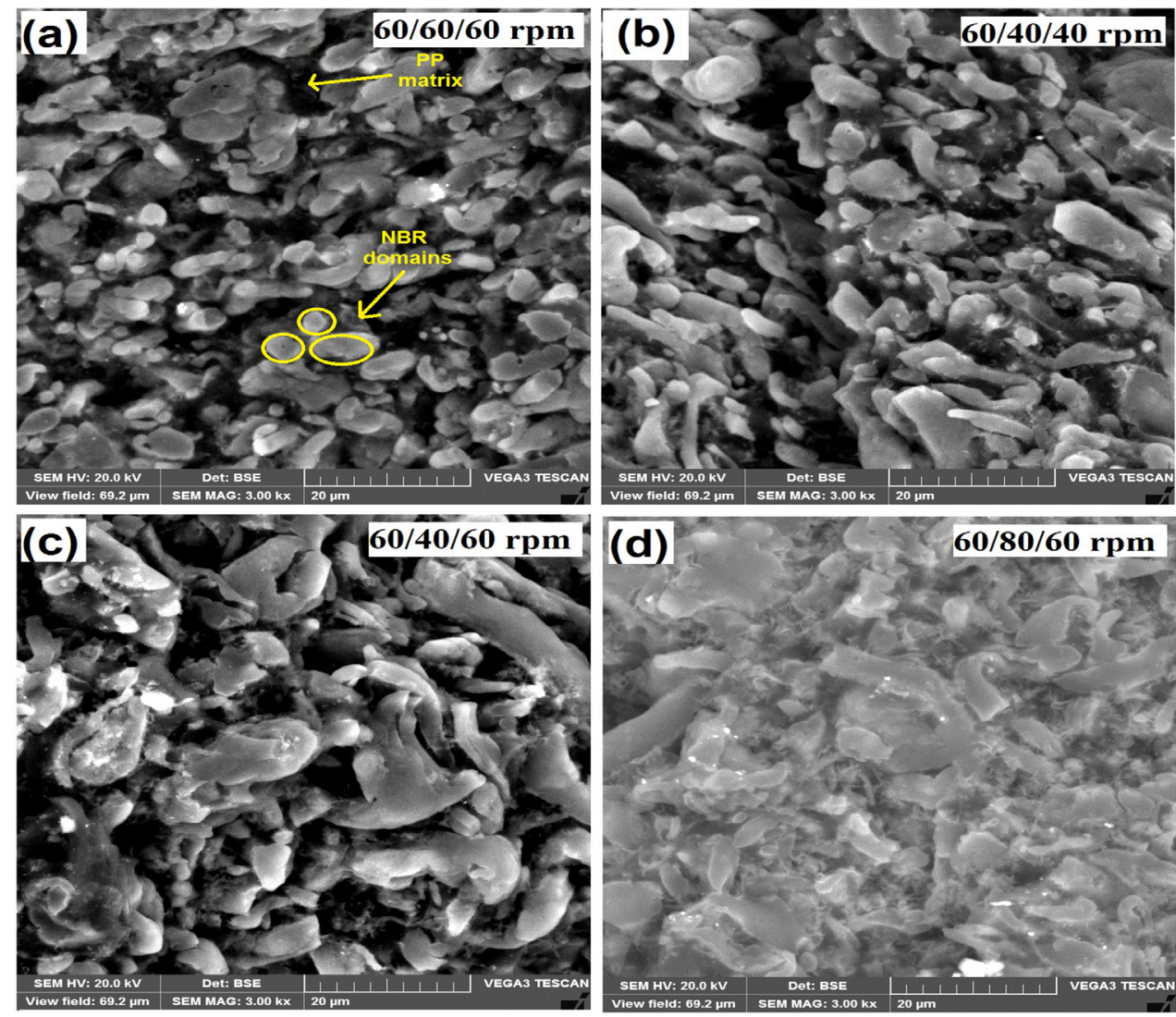

Figure 7. SEM micrographs of PP/NBR 30/70 mixed using speed profile V1 (a), V2 (b), V3(c) and V4 (d). 

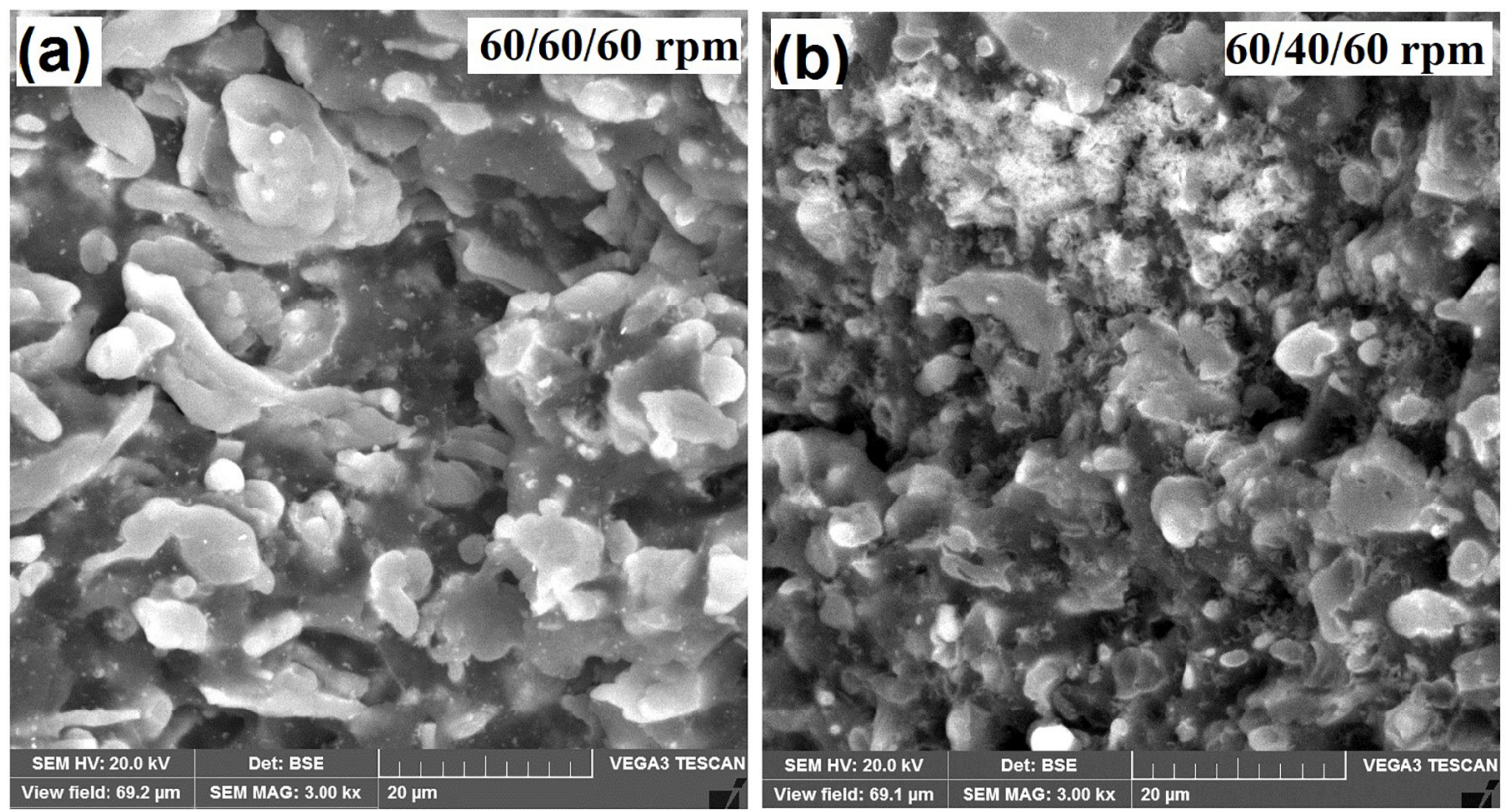

Figure 8. SEM micrographs of PP/NBR 50/50 mixed using speed profile V1 (a) and V3 (b).

therefore, on morphology. The rest of mixer did not show morphology with well-defined domains. The TPV processed with an increase in rotor speed during vulcanization (V4) shows in Figure 7-d that the phase inversion was not achieved as expected. Probably, $80 \mathrm{rpm}$ is too much. The morphology is in agreement of torque rheometer and the compression set and oil resistance results.

\subsection{Crystallization behavior}

Table 4 shows the results of thermograms obtained by DSC technique. It can be seen that the $\mathrm{T}_{\mathrm{m}}$ values do not vary significantly. However, the crystallization behavior was affected. Since the PP pure presents a $X_{c}$ value of $27 \%$, the theoretical values for TPVs with 30 PHR and 50 PHR of PP should be $8 \%$ and $13 \%$, respectively. It was also noticed an increase in T of PP into TPVs. The increase of $8^{\circ} \mathrm{C}$ on $\mathrm{T}_{\mathrm{c}}$ values is another one evidential of the interaction between PP and NBR promoted by BMI. This interaction affected the packing ability of PP chains, which is related to crystallite perfection and $X_{c}$, causing a nucleation effect. In turn, this effect decreases the size of the PP spherulites providing rapid crystallization of the polymer from the molten state and increasing $T_{c}$. The Table 4 shows that $T_{c}$ values were influenced by speed profile: when the systems were

Table 4. Rotor speed effect on the thermal properties of the TPVs.

\begin{tabular}{lcccc}
\hline Sample & $\mathbf{T}_{\mathbf{c}}\left({ }^{\circ} \mathbf{C}\right)$ & $\mathbf{T}_{\mathbf{m}}\left({ }^{\circ} \mathbf{C}\right)$ & Heat of fusion $(\mathbf{J} / \mathbf{g})$ & $\mathbf{X}_{\mathbf{c}}(\mathbf{\%})$ \\
\hline PP & 103 & 165 & 55.52 & 27 \\
\hline Rotor speed profile & & $\mathbf{T P V}$ PP/NBR (30/70 phr) & 9.7 \\
V1 & 108 & 167 & 20.09 & 10.2 \\
V2 & 111 & 164 & 21.14 & 9.8 \\
V3 & 111 & 165 & 20.27 & 10.6 \\
V4 & 109 & 166 & 21.01 & 15.7 \\
\hline Rotor speed profile & & TPV PP/NBR (50/50 phr) & 32.51 & 16.8 \\
V1 & 108 & 168 & 34.83 & \\
V3 & 111 & 166 & & \\
\hline
\end{tabular}

$\mathrm{T}_{\mathrm{c}}=$ crystallization temperature;

$\mathrm{T}_{\mathrm{m}}=$ melting temperature;

$\mathrm{X}_{\mathrm{c}}=$ crystallinity degree.

$\mathrm{V} 1=60 / 60 / 60 \mathrm{rpm}$;

$\mathrm{V} 2=60 / 40 / 40 \mathrm{rpm}$;

$\mathrm{V} 3=60 / 40 / 60 \mathrm{rpm}$;

$\mathrm{V} 4=60 / 80 / 60 \mathrm{rpm}$. 
processed reducing the rotor speed during and after dynamic vulcanization (V2 and V3 profiles), for both compositions, the interactions between PP and NBR promoted by BMI can be increased.

\section{Conclusions}

First, according to the results shown in this work, TPVs based on PP/NBR with morphology and reasonable properties were successfully achieved without the use of plasticizer or another compatibilizer agent, only studying the effect of processing conditions as the rotor speed. Further, the multipurpose action of BMI coagent was shown. The torque rheometer results shows that reducing rotor speed on dynamic vulcanization and increase it on mixing torque stabilization (V1 and V3) provides the best values of elastic torque, better dispersion of vulcanizes domains on PP matrix and major stability to TPV, besides decreasing the energy expenditure of the process. The speed and lower rubber content affected the crosslinking density of PP/NBR blends improving the tensile properties. The compression set shows that $\mathrm{V} 1$ and $\mathrm{V} 2$ profile provides greater crosslinking density to elastomeric phase in PP/NBR 50/50 blends. On the other hand, the V1 profile was really better for crosslinking efficiency and was confirmed by oil resistance. Finally, decrease rotor speed of internal mixer during dynamic vulcanization or/and return to initial speed at mixing torque stabilization stage exerted a strong influence on the final properties. It allows development a material that can join the elasticity of rubber and the thermoplastic easy process, enabling the development of a TPV through a more economical process, using known materials and favoring reprocessing conditions.

\section{References}

1. He C, Zou H, Zhao S. Effect of the processing molding temperature on the crystalline structure and properties of acrylonitrilebutadiene rubber/trinylon thermoplastic vulcanizates. Journal of Applied Polymer Science. 2006;102(2):1374-1379. DOI: 10.1002/app.24141

2. Passador FR, Alzate Rojas GJ, Pessan LA. Thermoplastic Elastomers Based on Natural Rubber/Polypropylene Blends: Effect of Blend Ratios and Dynamic Vulcanization on Rheological, Thermal, Mechanical, and Morphological Properties. Journal of Macromolecular Science, Part B: Physics. 2013;52(8):11421157. DOI: $10.1080 / 00222348.2012 .756323$

3. Passador FR, Rodolfo A Jr, Pessan LA. In Situ Dynamic Vulcanization of Poly(Vinyl Chloride)/Acrylonitrile-butadiene Rubber Blends. Journal of Macromolecular Science, Part B: Physics. 2009;48(2):282-298. DOI: 10.1080/00222340802679607

4. Huang H, Ikehara T, Nishi T. Observation of morphology in EPDM/nylon copolymer thermoplastic vulcanizates by atomic force microscopy. Journal of Applied Polymer Science. 2003;90(5):1242-1248. DOI: 10.1002/app.12629
5. Cheremisinoff NP, Cheremisinoff PN. Elastomer Technology Handbook. 2nd ed. Boca Raton: CRC Press; 1993.

6. Drobny JG. Thermoplastic Elastomers Prepared by Dynamic Vulcanization. In: Drobny JG. Handbook of Thermoplastic Elastomers. Chap. 6. 2nd ed. Oxford: William Andrew Publishing; 2014.p. 195207. DOI: https://doi.org/10.1016/B978-0-323-22136-8.00006-5

7. Patel RP, Shin J. Compounding and Processing of Plastic/Rubber Blends. In: Isayev AI. Encyclopedia of Polymer Blends. Chap. 3. Weinheim: Wiley-VCH; 2011.p. 109-162. DOI: http://onlinelibrary. wiley.com/doi/10.1002/9783527805242.ch3/summary

8. Kruželák J, Sýkora R, Hudec I. Vulcanization of Rubber Compounds With Peroxide Curing Systems. Rubber Chemistry and Technology. 2017;90(1):60-88. DOI: 10.5254/rct.16.83758

9. Soares BG, de Oliveira M, Meireles D, Sirqueira AS, Mauler RS. Dynamically vulcanized polypropylene/nitrile rubber blends: The effect of peroxide/bis-maleimide curing system and different compatibilizing systems. Journal of Applied Polymer Science. 2008;110(6):3566-3573. DOI: 10.1002/app.28946

10. Soares BG, Almeida MSM, Leyva ME, SirqueiraAS. Mechanical and Morphological Properties of Polypropylene/Nitrile Butadiene Rubber Compatibilized Vulcanizates. KGK Rubberpoint. 2006;59(3):110114.

11. Pan J, Hu H, Huang Z, Duan Y. Study of nitrile-butadiene rubber and polypropylene (NBR/PP) grafting cross-linked system. PolymerPlastics Technology and Engineering. 2001;40(5):605-613. DOI: 10.1081/PPT-120000303

12. Xu C, Cao X, Jiang X, Zeng X, Chen Y. Preparation, structure and properties of dynamically vulcanized polypropylene/acrylonitrile butadiene rubber/zinc dimethacrylate ternary blend composites containing maleic anhydride grafted polypropylene. Polymer Testing. 2013;32(3):507-515. DOI: http://dx.doi.org/10.1016/j. polymertesting.2013.01.005

13. George S, Joseph R, Thomas S, Varughese KT. Blends of isotactic polypropylene and nitrile rubber: morphology, mechanical properties and compatibilization. Polymer. 1995;36(23):4405-4416. DOI: http://dx.doi.org/10.1016/0032-3861(95)96846-Z

14. Zhang X, Huang H,Zhang Y. Dynamically vulcanized nitrile rubber/ polypropylene thermoplastic elastomers. Journal of Applied Polymer Science. 2002;85(14):2862-2866. DOI: 10.1002/app.10884

15. George S, Ramamurthy K, Anand JS, Groeninckx G, Varughese KT, Thomas S. Rheological behaviour of thermoplastic elastomers from polypropylene/acrylonitrile-butadiene rubber blends: effect of blend ratio, reactive compatibilization and dynamic vulcanization. Polymer. 1999;40(15):4325-4344. DOI: http://dx.doi.org/10.1016/ S0032-3861(98)00681-8

16. Coran AY, Patel R, inventors; Monsanto, assignee. Compatibilized polymer blends. United States patent US 4355139A. 1982 Oct 19.

17. Ismail $H$, Galpaya $D, A h m a d Z$. The compatibilizing effect of epoxy resin (EP) on polypropylene (PP)/recycled acrylonitrile butadiene rubber (NBRr) blends. Polymer Testing. 2009;28(4):363-370. DOI: 10.1016/j.polymertesting.2008.11.007

18. George S, Varughese KT, Thomas S. Thermal and crystallisation behaviour of isotactic polypropylene/nitrile rubber blends. Polymer. 2000;41(14):5485-5503. DOI: http://dx.doi.org/10.1016/S00323861(99)00719-3 
19. Jose S, Aprem AS, Francis B, Chandy MC, Werner P, Alstaedt V, et al. Phase morphology, crystallisation behaviour and mechanical properties of isotactic polypropylene/high density polyethylene blends. European Polymer Journal. 2004;40(9):2105-2115. DOI: 10.1016/j.eurpolymj.2004.02.026

20. Magioli M, SirqueiraAS, Soares BG. The effect of dynamic vulcanization on the mechanical, dynamic mechanical and fatigue properties of TPV based on polypropylene and ground tire rubber. Polymer Testing. 2010;29(7):840-848. DOI: 10.1016/j.polymertesting.2010.07.008

21. Ma L, Bao R, Liu Z, Yang W, Yang M. Effect of cross-linking degree of EPDM phase on the electrical properties and formation of dual networks of thermoplastic vulcanizate composites based on isotactic polypropylene (iPP)/ethylene-propylene-diene rubber (EPDM) blends. RSC Advances. 2016;6(78):74567-74574. DOI: 10.1039/C6RA14731C

22. Silverstein RM, Webster FX, Kiemle DJ, Bryce DL. Spectrometric Identification of Organic Compounds. Hoboken: Wiley; 2014.

23. Shibata M, Teramoto N, Shimasaki T, Ogihara M. High-performance bio-based bismaleimide resins using succinic acid and eugenol. Polymer Journal. 2011;43:916-922.

24. El Tall O, Hou Y, Abou-Hamad E, Raja IU, Hedhili MN, Peng W, et al. Beaujuge. Direct Functionalization of Nanodiamonds with Maleimide. Chemistry of Materials. 2014;26(9):2766-2769. DOI: 10.1021/cm500036x
25. Harea E, Stocek R, Machovský M. Study of friction and wear of thermoplastic vulcanizates: the correlation with abraded surfaces topology. Journal of Physics: Conference Series. 2017;843:012070. DOI: https://doi.org/10.1088/1742-6596/843/1/012070

26. Coran AY. Vulcanization. In: Mark JE, Erman B, Eirich FR, eds. Science and Technology of Rubber. 3rd ed. Burlington: Academic Press; 2005. p. 321-366. DOI: https://doi.org/10.1016/ B978-012464786-2/50010-9

27. Antunes CF, Machado AV, van Duin M. Morphology development and phase inversion during dynamic vulcanisation of EPDM/ PP blends. European Polymer Journal. 2011;47(7):1447-1459. DOI: http://dx.doi.org/10.1016/j.eurpolymj.2011.04.005

28. Koning C, Van Duin M, Pagnoulle C, Jerome R. Strategies for compatibilization of polymer blends. Progress in Polymer Science. 1998;23(4):707-757. DOI: http://dx.doi.org/10.1016/ S0079-6700(97)00054-3

29. Babu RR, Singha NK, Naskar K. Phase morphology and melt rheological behavior of uncrosslinked and dynamically crosslinked polyolefin blends: role of macromolecular structure. Polymer Bulletin. 2011;66(1):95-118. DOI: 10.1007/s00289-010-0328-4

30. Babu RR, Singha NK, Naskar K. Effects of mixing sequence on peroxide cured polypropylene (PP)/ethylene octene copolymer (EOC) thermoplastic vulcanizates (TPVs). Part. I. Morphological, mechanical and thermal properties. Journal of Polymer Research. 2010;17(5):657-671. DOI: 10.1007/s10965-009-9354-z 